\title{
EFFECT OF HEMODIALYSIS ON INTRA-ABDOMINAL PRESSURE
}

\author{
Roberta Fernandes Bonfim, Andréia Grigório Goulart, Carolina Fu, Jamili \\ Anbar Torquato
}

Bonfim RF, Goulart AG, Fu C, Torquato JA. Effect of hemodialysis on the intra-abdominal pressure. Clinics. 2007;62(2): 145-50.

OBJECTIVE: To study the effect of hemodialysis on intra-abdominal pressure.

METHODS: Five patients admitted between July and November of 2003 were evaluated in the intensive care unit. Intra-abdominal pressure was measured before and after hemodialysis, maintaining the ventilatory parameters except for PEEP (positive-end expiratory pressure).

RESULTS: Intra-abdominal pressure was significantly reduced by hemodialysis in all the 5 patients.

CONCLUSION: Hemodialysis significantly reduced intra-abdominal pressure in the 5 patients, an effect which could have influence over other organic systems. This reduction is related to the weight variation before and after hemodialysis, as well as to the loss of volume caused by this procedure.

KEYWORDS: Renal dialysis. Abdomen. Physiotherapy. Mechanical ventilation. Intensive care unit.

\section{INTRODUCTION}

Hemodialysis is a broadly employed therapeutic procedure that is indispensable in the treatment of several clinical complications seen at intensive care units (ICUs). It is one of the most frequently used therapeutic methods for the treatment of renal failure, either chronic or acute. ${ }^{1}$ The mortality rate among critically ill patients with acute renal failure in ICUs is very high, and hemodialysis is frequently used in such patients with the objective of correcting metabolic disorders and controlling body volume, allowing, in some cases, the restoration of renal function, while maintaining homeostasis. ${ }^{2}$ The most well known and most broadly used technique is intermittent hemodialysis, which lasts 3 to 4 hours per session and can be used daily

Physical Therapy Facility, Hospital das Clínicas, São Paulo University Medical School - São Paulo/SP, Brazil.

Department of Physiotherapy, Communication Science and Disorders and Occupational Therapy, São Paulo University Medical School - São Paulo/ SP, Brazil.

Email: jamilianbar@yahoo.com

Received for publication on October 26, 2006.

Accepted for publication on December 13, 2006. or on alternate days, according to the patient's needs. ${ }^{3}$

The removal of solutes through a semi-permeable membrane during the hemodialysis occurs through 2 mechanisms: diffusion and convection. Diffusion is the movement of a solute from one side of the dialyzing membrane to the other side according to a gradient of concentration. This mechanism is primarily responsible for the removal of solutes during classical hemodialysis. The convection results from the ultrafiltration of the solvent generated by a gradient of hydraulic pressure that takes place through the dialyzer membrane. The solvent passes from one side of the membrane to the other side, drawing the solute through the membrane. Liquid removal is achieved through the same process of ultrafiltration generated by the transmembrane gradient of hydrostatic pressure. This hydrostatic pressure can be positive, when water is pushed from the plasma through the dialyzer membrane, or negative, when a vacuum is created in the dialyzed side, which will draw the water. ${ }^{3}$

The removal of liquids from the human body during a dialysis session generates a significant impact on the body's hydric balance. Although the exact amount of fluid lost by the different body parts is still not known, some studies 
have shown a significant decrease of the amount of fluid inside the chest cavity and the possible effects caused by the removal of this excess fluid on pulmonary function. ${ }^{4,5}$

Similarly to the chest cavity, the abdominal cavity also constitutes a closed space that comprises a limited volume. The increase in the volume of this cavity, caused by any dysfunction, leads to an increase in intra-abdominal pressure (IAP), which can bring severe consequences to the individual as a whole. ${ }^{5,7}$ The increase of this pressure can generate clinical pictures of intra-abdominal hypertension (IAH) that vary from moderate to severe (abdominal compartment syndrome-ACS). Regarding the degree of IAH, Malbrain ${ }^{8}$ proposed a IAP grading system as follows: grade 0 (IAP 0-7 mm Hg, normal); grade I (IAP 8-11 mm Hg, ambiguous condition, with a possibility of developing IAH); grade II (IAP 12-15 mm Hg, moderate IAH); grade III (IAP 16-20 mm Hg, severe IAH); grade IV (IAP 21-25 $\mathrm{mm} \mathrm{Hg}$, moderate ACS); grade V (IAP > $25 \mathrm{~mm} \mathrm{Hg}$, severe ACS).

Small increases in IAP can have adverse effects on the body, and some clinical measures can be taken in order to reduce this pressure (gastric emptying, rectal enema, paracentesis, use of diuretics, and adequate positioning of the patient on the bed). Patients with IAP of approximately 25 $\mathrm{mm} \mathrm{Hg}$ must undergo surgical procedures for abdominal decompression; however, it is important to remember that there is no consensus among authors regarding this value. ${ }^{8}$

Hemodialysis can also alter IAP by reducing the body volume, including abdominal volume. Nevertheless, a search of the literature did not disclose any study that correlated the removal of fluid promoted by hemodialysis and its effect on IAP.

Therefore, the aim of the present study was to verify, through preliminary findings, the influence of hemodialysis on IAP in a sample of 5 patients.

\section{METHODS}

Five patients admitted to the ICU of the Service of Nephrology of the Central Institute of Hospital das Clínicas of the School of Medicine of the University of São Paulo (ICHC/FMUSP) between July and November 2003 met the inclusion criteria (below) and were included in the study.

\section{Inclusion criteria:}

- Being older than 18 yrs of age;

- Undergoing hemodialysis;

- Using a Foley catheter, prescribed by a doctor and inserted according to the routine of the Service, to measure the intra-abdominal pressure;

- Having signed the written informed consent form, or when appropriate, having had the form signed by the legal guardian;

\section{Exclusion criteria:}

- Being hemodynamically unstable;

- Presenting $\mathrm{SatO}_{2}<90 \%$

- Having a contraindication for the horizontal dorsal decubitus position $\left(180^{\circ}\right)$

- Not using a Foley catheter.

IAP measurement. IAP measurement was carried out immediately before (pre-hemodialysis IAP) and $4 \mathrm{hr}$ after the hemodialysis (post-hemodialysis IAP).

Measurement of IAP was carried out according to the method of Kron et al, ${ }^{9}$ for which the patient must be using a Foley catheter. The measurement of the intravesical pressure is an indirect measurement of the IAP. A central venous pressure (CVP) device connected to the Foley catheter was used, through an 18-gauge needle. The outflow into the urine collector was clamped. Fifty $\mathrm{mL}$ of $0.9 \%$ sterile saline solution (SS) were infused into the patient's bladder through the catheter. The 0 pressure point in the numerical scale was considered to be the value that was level with the patient's pubic symphysis, with the patient positioned in the horizontal dorsal decubitus position. An external port of the CVP device, not connected to the SS or the vesical catheter was opened with the objective of equilibrating the intravesical pressure with the atmospheric pressure; the water column came down to a level associated with a value on the numerical scale, and this was considered the value for the IAP, counting from the predetermined 0 point of pressure. The value achieved during the expiratory phase was recorded. In patients under invasive mechanical ventilation (IMV) and noninvasive mechanical ventilation (NIMV), the ventilatory parameters were observed; however, they were not altered, with the exception of PEEP (positive-end expiratory pressure), which must have its values predetermined during IAP measurement. The patient started to be ventilated either with a PEEP at $5 \mathrm{~cm} \mathrm{H}_{2} \mathrm{O}$ or $10 \mathrm{~cm} \mathrm{H}_{2} \mathrm{O}$. Because there is an interaction between chest and abdominal cavities, measurements were carried out during the expiratory phase. ${ }^{6,7}$

A value of IAP in units of $\mathrm{cm} \mathrm{H}_{2} \mathrm{O}$ was obtained, and which was converted into $\mathrm{mm} \mathrm{Hg}$ (most commonly used for IAP). ${ }^{8}$

Data regarding the patient's dialysis (type of dialysis, duration, ultrafiltration, blood flow, dialyzed flow, adverse events, and infusions) were also collected from the medical prescription of the dialysis, along with personal data (age, gender, weight, height), the nephrological diagnosis, and other diagnoses of the patient. 
All of the data are presented as mean $\pm \mathrm{SD}$. The Student $t$ test was used to test for significant differences between the pre- and post-treatment means, with the level of significance set at $0.05(P<0.05)$. Pearson's coefficient of correlation, $r$, an index without dimension of between 1.0 and 1.0, was used to evaluate the correlation between 2 variables.

This study was approved by the Ethical Review Board of the Institution.

\section{RESULTS}

Five patients ( 3 males and 2 females) were evaluated, with mean age of $56 \pm 18$ years (range, 37-75 years). Two of these patients had a nephrological diagnosis of acuteon chronic renal failure (CRF) and 1 of CRF. All were undergoing mechanical ventilation and hemodialysis. Three patients underwent extended hemodialysis, and 2 underwent classical hemodialysis. Four patients had an indication for hemodialysis due to hypervolemia and 1 to uremia.

The present study showed that hemodialysis resulted in significantly reduced IAP in the 5 patients when they were ventilated with PEEP $5 \mathrm{~cm} \mathrm{H}_{2} \mathrm{O}$ (pre-hemodialysis IAP = $22.30 \pm 6.77 \mathrm{~mm} \mathrm{Hg}$ vs. post-hemodialysis IAP $=13.19 \pm$ $2.95 \mathrm{~mm} \mathrm{Hg}, P=0.01$ ) (Figure 1), as well as when they were ventilated with PEEP $10 \mathrm{~cm} \mathrm{H}_{2} \mathrm{O}$ (pre-IAP $=23.8 \pm$ $7.51 \mathrm{~mm} \mathrm{Hg}$ vs post-hemodialysis IAP $=15.23 \pm 2.43 \mathrm{~mm}$ $\mathrm{Hg}, \mathrm{P}=0.01$ ) (Figure 2).

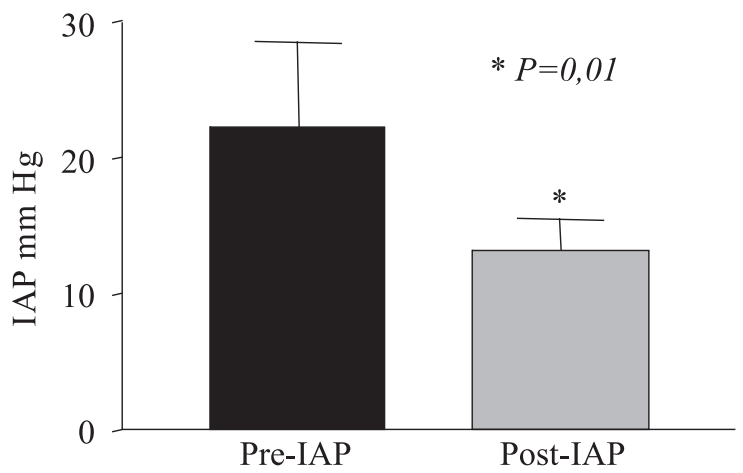

Figure 1 - Pre-hemodialysis intra-abdominal pressure (IAP) and 4 hours after the beginning of the procedure (post-hemodialysis, values in $\mathrm{mm} \mathrm{Hg}$ )

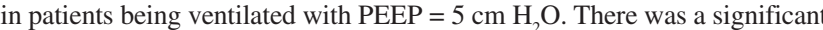
decrease in post-hemodialysis $\operatorname{IAP}(P=0.01)$.

There was no significant difference in pre- and posthemodialysis IAP when the patients were ventilated at different levels of PEEP $\left(5 \mathrm{~cm} \mathrm{H}_{2} \mathrm{O}\right.$ and $10 \mathrm{~cm} \mathrm{H}_{2} \mathrm{O}$ ). (Prehemodialysis IAP with PEEP $5=22.30 \pm 6.77 \mathrm{~mm} \mathrm{Hg}$ vs with PEEP $10=23.8 \pm 7.51 \mathrm{mmHg}, P=0.16$; posthemodialysis IAP with PEEP $5=13.19 \pm 2.95 \mathrm{~mm} \mathrm{Hg}$ vs with PEEP $10=15.23 \pm 2.43 \mathrm{~mm} \mathrm{Hg}, P=0.16$ ) (Figure 3).

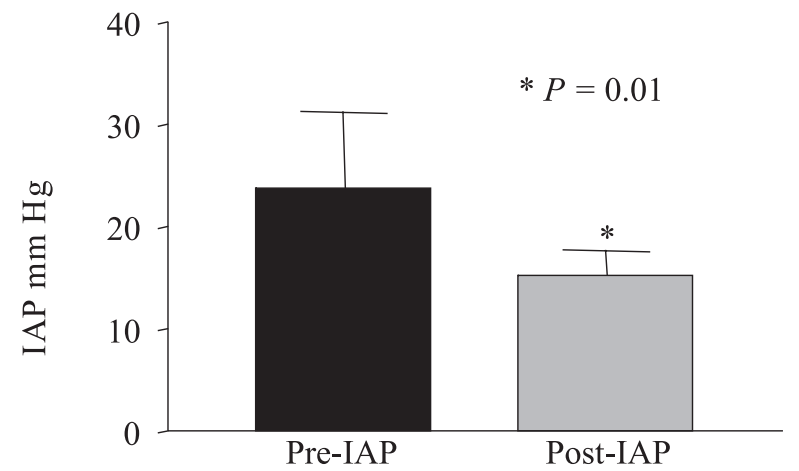

Figure 2 - Pre-hemodialysis intra-abdominal pressure (IAP) and 4 hours after the beginning of the procedure (post-hemodialysis), in patients being ventilated with PEEP $=10 \mathrm{~cm} \mathrm{H}_{2} \mathrm{O}$. There was a significant decrease in post-hemodialysis IAP $(P=0.01)$

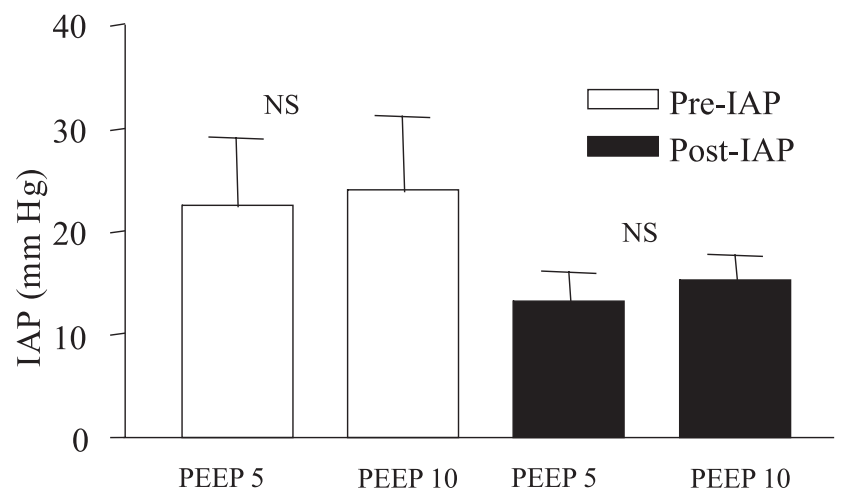

Figure 3 - Pre-hemodialysis intra-abdominal pressure (IAP) and 4 hours after the beginning of the procedure (post-hemodialysis), in patients being ventilated with different levels of PEEP ( $5 \mathrm{~cm} \mathrm{H}_{2} \mathrm{O}$ and $10 \mathrm{~cm} \mathrm{H}_{2} \mathrm{O}$ ). There was no significant difference in IAP associated with the different levels of PEEP for pre- and post-hemodialysis IAP $(P=0.16)$. There was no significant difference in pre- and post-hemodialysis IAP when the patients were ventilated at different PEEP levels $\left(5 \mathrm{~cm} \mathrm{H_{2 }} \mathrm{O}\right.$ and $10 \mathrm{~cm} \mathrm{H}_{2} \mathrm{O}$ ). (Prehemodialysis IAP with PEEP $5=22.30 \pm 6.77 \mathrm{~mm} \mathrm{Hg}$ versus PEEP $10=$ $23.8 \pm 7.51 \mathrm{~mm} \mathrm{Hg}, P=0.16$; post-hemodialysis IAP with PEEP $5=13.19$ $\pm 2.95 \mathrm{~mm} \mathrm{Hg}$ versus PEEP $10=15.23 \pm 2.43 \mathrm{~mm} \mathrm{Hg}, P=0.16$ ).

There was a strong correlation between a decrease in IAP and the patient's variation in body weight pre- versus post-hemodialysis (patients being ventilated with PEEP = $5 \mathrm{~cm} \mathrm{H}_{2} \mathrm{O}, r=0.77$; with PEEP $=10 \mathrm{~cm} \mathrm{H}_{2} \mathrm{O}, r=0.9$ ), although this variation in pre- and post-hemodialysis weight was not statistically significant (Pre-hemodialysis weight, $81.36 \pm 20.89 \mathrm{~kg}$ vs post-hemodialysis weight, $67.08 \pm$ $21.77 \mathrm{~kg}, P=0.16)$. It was also observed that the decrease in IAP was correlated with the hydric balance of the dialysis procedure $\left(\mathrm{PEEP}=5 \mathrm{~cm} \mathrm{H}_{2} \mathrm{O}, r=0.78\right.$; $\mathrm{PEEP}=10$ $\mathrm{cm} \mathrm{H}_{2} \mathrm{O}, r=0.89$ ).

\section{DISCUSSION}

The aim of this study was to show the influence of hemodialysis on intra-abdominal pressure (IAP) in a sample 
of 5 patients. To do that, IAP was measured immediately before and 4 hours after the beginning of the procedure.

The data show that hemodialysis resulted in significantly reduced IAP in the assessed patients $(P=0.01)$. This decrease may benefits the patient, since the increased IAP has several important adverse effects that include cardiovascular, renal, intestinal, neurological, and respiratory abnormalities. However, no variables were evaluated in our study that could show whether the IAP decrease was accompanied by a benefit to the other systems.

Sebert et $\mathrm{al}^{10}$ reported an increase in the minute volume $\left(\mathrm{V}_{\mathrm{E}}\right)$ after hemodialysis in patients with chronic renal failure. Chang-wen et $\mathrm{al}^{1}$ found alterations caused by the hemodialysis on the respiratory mechanics in mechanically ventilated patients. In the present study, there was a decrease in the minimum and maximum resistance of the airways and in the peak and plateau pressures as well as an increase in the auto-PEEP, but no alteration in static compliance was observed.

Huang et al $^{11}$ did not observe any significant alteration in $\mathrm{V}_{\mathrm{E}}$, dynamic compliance and expiratory flow resistance of the airways, but they did observe a decrease in the respiratory work and auto-PEEP after hemodialysis with ultrafiltration in patients under mechanical ventilation. ${ }^{11}$

Ridings et al $^{12}$ established a direct correlation between the increase in IAP and the increase of airway peak pressure and intrathoracic pressure. ${ }^{12}$ This increase in pulmonary pressures caused by the increase in IAP is a mechanical alteration, because increased IAP elevates the diaphragm which in turn decreases thoracic volume and compliance, with the consequent increase in intrapleural pressure. ${ }^{6,7}$

We also observed that ventilation of patients with either PEEP 5 or $10 \mathrm{~cm} \mathrm{H}_{2} \mathrm{O}$ did not appear to affect the IAP value. This information is in agreement with reports in the literature that show that PEEP effects below $15 \mathrm{~cm} \mathrm{H}_{2} \mathrm{O}$ on IAP are unimportant. ${ }^{8,13}$

Although most of the alterations found in the respiratory system after hemodialysis are attributed to the reduction in the amount of fluid inside the chest cavity, other factors can also be related to such alterations. IAP is altered after hemodialysis and this can contribute to the alterations that occur in the respiratory system.

In addition to pulmonary alterations, IAP affects the cardiovascular and neurological systems as well as the abdominal viscera as a whole.

A 10 -to-15 mm Hg increase in IAP is enough to cause a decrease cardiac output due to decreased preload and increased postload. Both are consequent to increased venous resistance in the abdomen and chest, leading to a reduction in the venous return (preload decrease), which may or may not be compensated by an increase in the cardiac frequency. ${ }^{12,14}$
Renal function is also affected by increased IAP: values between 15 and $20 \mathrm{~mm} \mathrm{Hg}$ cause oliguria, whereas a IAP $>30 \mathrm{~mm} \mathrm{Hg}$ can cause anuria. ${ }^{15}$ The etiology of renal dysfunction is multifactorial and can be explained by the decrease in cardiac output and/or mechanical compression of the parenchyma and renal vessels, or even by the increased levels of circulating antidiuretic hormone (ADH) caused by the hemodynamic alterations. ${ }^{7}$

IAP also produces an increase in the intracranial pressure (ICP) and decreased cerebral perfusion as a consequence of the increased pleural pressure, which also impairs the cerebral venous return via jugular vein. ${ }^{7}$

The intestine is extremely sensitive to increased IAP. A small increase $(10 \mathrm{~mm} \mathrm{Hg})$ can reduce the mesenteric blood flow. ${ }^{16}$ This hypoperfusion can be one of the mechanisms responsible for the loss of effectiveness of the intestinal mucosal barrier and the subsequent translocation of bacteria to the bloodstream, which can cause sepsis and multiple-organ failure. ${ }^{17}$

It was also shown in the present study that a decrease in IAP is related to the reduction of body volume promoted by dialysis through the hydric balance and the weight variation that the patient undergoes before versus after the procedure. No previous report was found associating hemodialysis with IAP. However, this study shows that hemodialysis can cause a significant decrease in this variable: 1 patient underwent a $60 \%$ decrease in the IAP after the dialysis, going from a degree III of IAP to degree I. A limitation of this study is that only IAP was assessed, not other body systems. Thus, additional studies are needed involving more patients, consequently increasing the sample size, together with including other variables, such as cardiac output, intracranial pressure, and respiratory mechanics. Such studies could further clarify the effect of hemodialysis on IAP, as well as verify the impact of this reduction on the other body systems, demonstrating the clinical benefits of the procedure.

\section{CONCLUSION}

Hemodialysis significantly decreased IAP of the 5 patients assessed. This reduction is related to the physiological effects of the procedure, ie, the loss of body fluid volume and consequent decrease of body weight after the procedure, influencing other organs and consequently decreasing IAP. The present study presents a new observation, not previously described in literature; these results are not absolute, but rather are preliminary observations that show a tendency for reduction of IAP through hemodialysis. Further studies with larger cohorts are necessary to support this preliminary report. 
Bonfim RF, Goulart AG, Fu C, Torquato JA. Efeito da hemodiálise sobre a pressão intra-abdominal. Clinics. 2007;62(2): 145-50.

OBJETIVO: Pesquisar o efeito da hemodiálise sobre a pressão intra-abdominal.

MÉTODOS: Foram avaliados cinco pacientes internados entre julho e novembro de 2003, na Unidade de Terapia Intensiva do Serviço de Nefrologia do Hospital das Clínicas de São Paulo. Mensurou-se a pressão intra-abdominal antes e após a hemodiálise, mantendo os parâmetros ventilatórios exceto a PEEP (positive end expiratory pressure).
RESULTADOS: Constatou-se que a hemodiálise foi capaz de reduzir significativamente a PIA em cinco pacientes na Unidade de Terapia Intensiva

CONCLUSÃO: A hemodiálise reduziu a pressão intra-abdominal numa amostra de cinco pacientes, de maneira significativa, o que poderia influenciar os demais sistemas orgânicos. Essa redução está relacionada com a variação de peso pré e pós-hemodiálise, e com a perda de volume promovida pelo procedimento.

UNITERMOS: Diálise Renal. Abdome. Fisioterapia. Respiração Mecânica. Unidade de Terapia Intensiva.

\section{REFERENCES}

1. Chang-Wen C, Cheng-Hung L, Han-Yu C, Tzuen-Ren H, Junne-Ming S, Jeng-Jong H. Respiratory mechanics after hemodialysis in mechanically ventilated patients. J Formos Med Assoc. 1998;97:2717.

2. Schiffl H, Lang S M, Fischer R. Daily hemodialysis and the outcome of acute renal failure. N Engl J Med. 2002;346:305-10.

3. Daugirdas JT, Vanstone JC. Physiologic principles and urea kinetic modeling. In: Daugirdas JT, Blake PG, Tood SI, editors. Handbook of Dialysis. $3^{\text {rd }}$ ed. Philadelphia; Lippincott Williams \& Wilkins: 2001.

4. Noordegraaf A, van der Meer BJ, de Vries JP, de Vries PM. Determination of the relation between alterations of total body water and thoracic fluid content during ultrafiltration by bioelectrical impedance analysis. Nephrol Dial Transplant. 1995;10:382-5.

5. Keller G, Blumberg A. Monitoring of pulmonary fluid volume and stroke volume by impedance cardiography in patients on hemodialysis. Chest. 1977;72:56-62.

6. McNelis J, Marini CP, Simms HH. Abdominal compartment syndrome: clinical manifestations and predictive factors. Curr Opin Crit Care. 2003;9:133-6.
7. Bloomfield G L, Ridings P C, Blocher C R, Marmarou A, Sugerman H J. A proposed relationship between increased intra-abdominal, intrathoracic, and intracranial pressure. Crit Care Med. 1997;25:496503.

8. Malbrain M. Abdominal perfusion pressure as a prognostic marker in intra-abdominal hypertension. In: Vincent J L, editor. Year Book of Intensive Care and Emergency Medicine. Berlin; Springer: 2002, p 792814 .

9. Kron IL, Harman PK, Nolan AP. The measurement of intra-abdominal pressure as a criterion for abdominal re-exploration. Ann Surg. 1984;199:28-30.

10. Sebert P, Bellet M, Girin E, Cledes J, Barthelemy L. Ventilatory and occlusion pressure responses to hypercapnia in patients with chronic renal failure. Respiration. 1984;45:191-6.

11. Huang CC, Tsai YH, Lin MC, Yang CT, Hsieh MJ, Lan RS. Respiratory drive and pulmonary mechanics during haemodialysis with ultrafiltration in ventilated patients. Anaesth Intens Care. 1997;25:46470. 
12. Ridings PC, Bloomfield GL, Blocher GR, Sugerman HJ. Cardiopulmonary effects of raised intra-abdominal pressure before and after intravascular volume expansion. J Trauma. 1995;39:1071-75.

13. Malbrain M. Abdominal pressure in the critically ill. Curr Opin Crit Car.e 2000;6:17-29.

14. Cullen DJ, Coyle JP, TeplickR, Long MC. Cardiovascular, pulmonary, and renal effects of massively increased intra-abdominal pressure in critically ill patients. Crit Care Med. 1989;17:118-21.
15. Bradley SE. The effect of increased intra-abdominal pressure on renal function in man. J Clin Invest. 1947;26:1010.

16. Diebel LN, Dulchavsky SA, Brown WJ. Splanchnic ischemia and bacterial translocation in the abdominal compartment syndrome. J Trauma. 1997;43:852-55

17. Sugerman HJ, Bloomfield GL, Saagi BW. Multisystem organ failure secondary to increased intraabdominal pressure. Infection. 1999;27:616 